\title{
Menumbuhkan nasionalisme di kalangan remaja kelompok seni musik Patrol Perkusi Bendho Agung di Desa Gadungsari Kecamatan Tirtoyudo Kabupaten Malang
}

\author{
Dini Dwi Dista Ramadina, Rosyid Al Atok, Didik Sukriono* \\ Universitas Negeri Malang, Jl. Semarang No. 5 Malang, Jawa Timur, Indonesia \\ *Penulis korespondensi, Surel: didik.sukriono.fis@um.ac.id
}

Paper received: 03-02-2021; revised: 15-02-2021; accepted: 28-02-2021

\begin{abstract}
This study aims to describe how to grow an attitude of nationalism, the appearance of nationalism, obstacles in developing nationalism, and those efforts are made to overcome obstacles to developing nationalism among youths Bendho Agung Percussion Patrol Music Art Group. This study uses a qualitative approach with descriptive research type. Data collection was carried out by means of observation, interviews, and documentation study. Data analysis using interactive analysis. Checking the validity of the data using triangulation techniques. how to grow an attitude of nationalism among adolescents with doing various activities includes of dancing traditional dances and playing traditional percussion patrol instruments such as kenong, saron, tambourine, drums, plastic drum, iron drum, gong and all members should to memorize the national song and folk songs. The appearance of nationalism is that the members t-shirts have nuances or patterns of batik and it doesn't have feeling inferior or inferiority when playing traditional musical instruments and dancing traditional dances. The develeoping nationalism among youths is also inseparable from the obstacles when realizing nationalism among youths Bendho Agung Percussion Patrol Music Art Group, these obstacles are the include the time clashes between school time and the time of the event and the lack of dance costumes of Bendho Agung Percussion Patrol Music Art Group. In overcoming these obstacles the Bendho Agung Percussion Patrol Music Art Group makes efforts to overcome them by giving permission to schools and borrow or rent dance costumes in an art studio Turen.
\end{abstract}

Keywords: nationalism; youth; Percussion Patrol Music Art Group.

\begin{abstract}
Abstrak
Kajian ini bertujuan mendiskripsikan cara menumbuhkan nasionalisme, bentuk perwujudan nasionalisme, kendala yang dihadapi dalam menerapkan nasionalisme, dan solusi dalam menghadapi kendala penerapan nasionalisme di kalangan remaja Kelompok Seni Musik Patrol Perkusi Bendho Agung. Kajian ini menggunakan pendekatan kualitatif dengan jenis penelitian deskriptif. Pengumpulan data dilakukan dengan cara observasi, wawancara, dan studi dokumentasi. Analisis data menggunakan analisis interaktif. Pengecekan keabsahan data menggunakan triangulasi sumber. Cara menumbuhkan sikap nasionalisme di kalangan remaja diantaranya melalui kegiatan menari tari tradisional, bermain alat musik tradisional patrol perkusi seperti kenong, dig dug, saron, rebana, kendang, drum plastik, drum besi, gong dan mewajibkan seluruh anggota untuk hafal lagu nasional dan lagu-lagu daerah. Bentuk perwujudan nasionalisme diantaranya kaos anggota ada nuansa atau corak batik dan tidak ada rasa minder atau rendah diri ketika bermain alat musik tradisional dan menari tarian tradisional. Dalam menumbuhkan nasionalisme di kalangan remaja tidak lepas dari kendala-kendala yang muncul saat mewujudkan nasionalme di kalangan renaja Kelompok Seni Musik Patrol Perkusi Bendho Agung, kendala tersebut yaitu waktu yang bentrok antara waktu sekolah dengan waktu event dan_kurangnya kostum tari yang dimiliki Kelompok Seni Musik Patrol Perkusi Bendho Agung. Dalam mengatasi kendala-kendala tersebut, Kelompok Seni Musik Patrol Perkusi Bendho Agung melakukan upaya-upaya dalam mengatasinya dengan cara memberian surat izin ke sekolah dan meminjam atau menyewa kostum tari di sanggar seni Turen.
\end{abstract}

Kata Kunci: nasionalisme; remaja; Kelompok Seni Musik Patrol Perkusi. 


\section{Pendahuluan}

Nasionalisme merupakan rasa mencintai keberagaman yang muncul dalam diri individu untuk hidup bersama dalam kehidupan berbangsa dan bernegara. Nasionalisme sangat penting diterapkan dalam kehidupan berbangsa dan bernegara agar keberagamaan tidak menjadikan bangsa Indonesia terpecah belah, apalagi jika kita melihat bahwa bangsa Indonesia adalah bangsa yang kaya akan kebudayaan dan hampir setiap daerah di seluruh Indonesia memiliki adat istiadat, suku, bahasa dan kebiasaan yang berbeda. Keanekaragaman budaya yang ada di Indonesia harus dipandang sebagai sebuah kekayaan bukan kemiskinan maupun sebagai ancaman pemecah bangsa. Kesenian merupakan bagian dari kebudayaan yang lahir dari karya cipta, karsa, dan rasa masyarakat sehingga menunjukkan karakteristik daerah masing-masing yang biasanya dilakukan secara turun temurun. Karya seni yang tercipta mencerminkan asal daerahnya bahkan dijadikan sebuah kekhasan dari daerah tertentu. Banyak sekali macam-macam kesenian di Indonesia mulai dari kesenian yang bersumber dari nenek moyang maupun berasal dari budaya yang telah dikembangkan oleh masyarakat saat ini dan juga generasi muda.

Kesenian merupakan bagian dari budaya dan juga dijadikan sebagai sarana untuk mengekspresikan rasa keindahan dari dalam jiwa manusia entah itu melalui gerakan, visual (penglihatan), dan audio (suara). Kesenian didalamnya terdapat berbagai macam seni misalnya seni tari, seni rupa, seni ukir, seni lukis, dan seni musik. Seni musik banyak dikembangkan oleh kalangan remaja dengan menggabungkan berbagai macam alat musik tradisional menjadi perpaduan yang selaras sehingga indah ketika didengarkan dan dapat diterima diberbagai kalangan masyarakat, salah satunya yaitu seni musik patrol perkusi dimana alat musik yang dimainkan merupakan gabungan alat musik yang dimainkan dengan cara digoyang, ditabuh, dipukul menggunakan alat maupun hanya dengan bantuan tangan kosong sehingga ketika dimainkan alat musik tersebut dapat menghasilkan bunyi atau suara. Seni musik perkusi adalah instrumen musik yang berperan memberikan kekuatan irama dan tempo dalam setiap komposisi musik yang menggunakannya. Seni musik patrol perkusi ini tidak terbatas pada alat musik yang pakem saja, melainkan semua benda yang dapat dipukul dan menghasilkan bunyi itu dapat digunakan sebagai pendukung suara dalam seni musik patrol perkusi. Kata patrol dalam seni musik patrol perkusi ini juga dikarenakan adanya alat musik kentongan yang mendorong cipta suara yang indah sehingga orang yang mendengarkan dapat menikmati dari perpaduan alat musik perkusi dan kentongan atau patrol tersebut agar tidak terkesan monoton.

Dengan demikian salah satu pendiri dari kelompok seni musik patrol perkusi di Kabupaten Malang yaitu Bapak Andri dan dinamakan "Bendho Agung". Pembentukan Kelompok Seni Musik Patrol Perkusi Bendho Agung didasarkan pada permasalahan di lingkungan masyarakat Desa Gadungsari yaitu belum terdapat kesenian apapun yang dapat dijadikan wadah maupun memotivasi masyarakat dari berbagai kalangan untuk mengekspresikan diri dengan berkreativitas sekaligus melestarikan budaya Indonesia yang beragam sebagai bentuk nasionalisme. Masyarakat Desa Gadungsari sebelumnya juga belum mengenal alat musik tradisional terutama alat musik perkusi ini karena kurangnya wawasan dan wadah mereka untuk mengeksperikan diri dengan belajar bermain alat musik. Ciri khas Kelompok Seni Musik Patrol Perkusi Bendho Agung dalam menarik minat masyarakat diantaranya alat musik kentongan dari bambu yang dapat memunculakan perbedaan diantara seni musik yang lain dengan diiringi tari tradisional asli buatan anggota remaja perempuan dan kereta hias berbentuk naga Kelompok Seni Musik Patrol Perkusi Bendho Agung. 
Berdasarkan pemikiran dan paparan di atas, peneliti tertarik untuk mengkaji lebih dalam tentang menumbuhkan nasionalisme di kalangan remaja Kelompok Seni Musik Patrol Perkusi Bendho Agung melalui penelitian dengan menggali informasi sebagai berikut. (1) cara menumbuhkan sikap nasionalisme di kalangan remaja Kelompok Seni Musik Patrol Perkusi Bendho Agung, (2) bentuk perwujudan nasionalisme di kalangan remaja Kelompok Seni Musik Patrol Perkusi Bendho Agung, (3) kendala yang dihadapi dalam menerapan nasionalisme di kalangan remaja Kelompok Seni Musik Patrol Perkusi Bendho Agung, dan (4) solusi dalam menghadapi kendala penerapan nasionalisme di kalangan remaja Kelompok Seni Musik Patrol Perkusi Bendho Agung.

\section{Metode}

Penelitian mengenai Menumbuhkan Nasionalisme di Kalangan Remaja Kelompok Seni Musik Patrol Perkusi Bendho Agung di Desa Gadungsari Kecamatan Tirtoyudo Kabupaten Malang menggunakan pendekatan kualitatif dan jenis penelitian deskriptif. Dalam pendekatan ini akan diperoleh untuk memperoleh data yang mendekati realita. Pendekatan ini mencoba untuk menggambarkan tentang gambaran umum Kelompok Seni Musik Patrol Perkusi Bendho Agung, cara menumbuhkan, bentuk perwujudan kendala, upaya dalam menumbuhkan nasionalisme di kalangan remaja Kelompok Seni Musik Patrol Perkusi Bendho Agung di Desa Gadungsari Kecamatan Tirtoyudo Kabupaten Malang. Penelitian kualitatif (Qualitatif reserch) adalah penelitian yang digunakan untuk mendapatkan data yang mendalam dan data yang mengandung makna dengan menyajikan secara langsung hakikat hubungan antar peneliti dan informan, objek dan subjek penelitian (Sugiyono, 2012:3).

Kehadiran peneliti pada kajian ini menjadi hal yang berperan penting karena kehadiran peneliti selain sebagai pelaksana, pengamat, juga menjadi pengumpul data yang akan mempengaruhi hasil dari penelitian yang dilakukan. Dalam penelitian ini peneliti terjun langsung ke lapangan untuk mengamati dan mengumpulkan data yang dibutuhkan untuk mendapatkan data yang sebenar-benarnya. Proses pengumpulan data dalam penelitian ini dilakukan dengan menggunakan 3 teknik yaitu teknik observasi, teknik wawancara, dan teknik dokumentasi. Teknik analisis data dalam kajian ini menggunakan analisis data kualitatif deskriptif. Pada penelitian ini menggunakan analisis data dengan model Miles dan Huberman atau disebut analisis interaktif. sebagaimana yang dikutip oleh (Ilyas, 2016:94) analisis data menggunakan model dari Miles dan Huberman yang membagi kegiatan analisis menjadi beberapa bagian yaitu: pengumpulan data, reduksi data, penyajian data, dan penarikan kesimpulan atau verifikasi data.

Pengecekan keabsahan data pada kajian ini menggunakan teknik triangulasi sumber. Penelitian kualitatif dalam pengecekan keabsahan data menggunakan model Triangulasi artinya mengulang atau klarifikasi dengan aneka sumber. Jika diperlukan triangulasi data, dapat dilakukan dengan cara mencari data-data lain sebagai pembanding. Orang yang terlibat dapat dimintai keterangan lebih lanjut tentang data yang diperoleh. Jika triangulasi pada aspek metode, perlu meninjau ulang metode yang digunakan dokumentasi, observasi, catatan lapangan dll (Sugiyono, 2014:267). 


\section{Hasil dan Pembahasan}

\subsection{Kelompok Seni Musik Patrol Perkusi Bendho Agung}

Kelompok Seni Musik Patrol Perkusi Bendho Agung merupakan kelompok seni yang berada di Desa Gadungsari RT 03 RW 02, Kecamatan Tirtoyudo, Kabupaten Malang. Desa Gadungsari secara geografis terletak di kawasan dataran tinggi dengan ketinggian mencapai 0$1100 \mathrm{Mdpl}$ dan di bawah lereng Gunung Semeru. Pemilihan lokasi ini dikarenakan tempatnya yang strategis yakni berada dilingkungan warga kampung yang mendukung penuh kegiatan Kelompok Seni Musik Patrol Perkusi Bendho Agung dan 90\% anggotanya berada di wilayah tersebut. Kegiatan Kelompok Seni Musik Patrol Perkusi Bendho Agung lebih tepatnya dilaksanakan di pendopo berukuran 5x3 meter dan di sepanjang jalan Kampung Dongki sekitar 200 meter.

Awal mula berdirinya Kelompok Seni Musik Patrol Perkusi Bendho Agung pada tahun 2012 pada saat bulan Ramadhan, ide ini muncul dari salah satu warga yaitu Bapak Mulyadi yang terinspirasi dari gugah sahur pada bulan Ramadhan, melihat keantusiasan warga ketika ikut dalam gugah sahur dengan memainkan alat musik seadanya kemudian didirikannya sebuah kelompok seni musik patrol perkusi ini. kemudian pada tahun 2013 mereka memberanikan diri untuk ikut dalam lomba di Bakroto Kecamatan Ampelgading dengan alat seadanya dan modal alat musik pinjaman, kemudian pada tahun 2015 seluruh anggota bergotong royong membuat kereta hias dari mobil bekas yang dihias agar terlihat lebih indah. Bermula dari situlah Kelompok Seni Musik Patrol Perkusi Bendho Agung semakin berniat untuk memperbaiki dan ikut serta dalam lomba-lomba dan parade.

Pembentukan Kelompok Seni Musik Patrol Perkusi Bendho Agung tidak luput dari gotong royong, kerja keras dan kerjasama masyarakat Kampung Dongki atau masyarakat Desa Gadungsari RT 03 RW 02 dalam mendirikan Kelompok Seni Musik Patrol Perkusi Bendho Agung dengan donator terbesarnya Bapak Eko. Kelompok Seni Musik Patrol Perkusi Bendho Agung merupakan kesenian yang masih berusia muda, namun respon masyarakat sekitar dengan hadirnya Kelompok Seni Musik Patrol Perkusi Bendho Agung di daerah ini disambut baik oleh masyarakat meskipun masih ada pro dan kontra namun, mayoritas masyarakat sangat mendukung dalam melestarikan budaya dalam wadah Kelompok Seni Musik Patrol Perkusi Bendho Agung.

Nama Bendho Agung terdiri dari kata "Bendho" nama Bendho terinspirasi dari awal mula berdirinya Kelompok Seni Musik Patrol Perkusi ini yaitu di Bendho Agung atau sungai besar yang letaknya persis di belakang pendopo tempat berlatih Kelompok Seni Musik Patrol Perkusi Bendho Agung. Nama tersebut dihubungkan dengan seni tradisi agar lebih identik dengan sejarah berdirinya Kelompok Seni Musik Patrol Perkusi Bendho Agung.

Jumlah anggota Kelompok Seni Musik Patrol Perkusi Bendho Agung yaitu 37 orang, dari data tersebut menunjukkan bahwa antusias masyarakat dalam ikut serta melestarikan budaya daerah melalui patrol perkusi dibilang tinggi karena bukan hanya anggota saja yang antusias ikut serta melestarikan budaya, namun masyarakat sekitar dan pemerintah Desa Gadungsari juga ikut mendukung akan adanya Kelompok Seni Musik Patrol Perkusi Bendho Agung. Keantusiasan anggota Kelompok Seni Musik Patrol Perkusi Bendho Agung dapat dilihat dari usia anggota yang ikut serta dalam Kelompok Seni Musik Patrol Perkusi Bendho Agung yaitu usianya mulai dari anak usia Taman Kanak-kanak hingga lanjut usia. Kelompok Seni Musik 
Patrol Perkusi Bendho Agung tidak membatasi usia anggota maupun calon anggota yang ingin ikut serta dalam Kelompok Seni Musik Patrol Perkusi Bendho Agung karena dalam kelompok seni ini yang dilihat adalah kemauan dalam belajar. Anggota Kelompok Seni Musik Patrol Perkusi Bendho Agung yang berusia remaja rata-rata berumur 13-19 tahun dan masih duduk dibangku sekolah yaitu siswa SMP kelas 7,8 \& 9 dan siswa SMA kelas 10,11 \& 12 yang sangat antusias belajar alat musik maupun tari-tarian dalam wadah Kelompok Seni Musik Patrol Perkusi Bendho Agung karena dari ikut serta menjadi anggota kelompok seni ini mereka dapat belajar dan menemukan bakat terpendam yang sebelumnya mereka sendiri belum pernah tau jika mereka bisa.

Kelompok Seni Musik Patrol Perkusi Bendho Agung mempunyai susunan keorganisasian sangat jelas, susunan keorganisasian pengurus inti Kelompok Seni Musik Patrol Perkusi Bendho Agung yang terdiri dari penanggung jawab; ketua; wakil ketua; sekertaris; bendahara; penasehat; humas; koordinator seni tari; koordinator seni musik; koordinator dekorasi; koordinator perlengkapan dan anggota Kelompok Seni Musik Patrol Perkusi Bendho Agung.

Lambang dari Kelompok Seni Musik Patrol Perkusi Bendho Agung menggunakan kereta berbentuk naga dan terdapat lambang pada benner yaitu ada gambar kepala singa yang berartikan asli anak Malang dan di sebelah kanan kirinya ada naga dan gambar gong di atasnya. Berdirinya Kelompok Seni Musik Patrol Perkusi Bendho Agung bertujuan untuk mempersatukan masyarakat Kampung Dongki agar guyub rukun dalam bermasyarakat melalui kelompok patrol perkusi. Tujuan yang kedua yaitu untuk memperkenalkan kepada masyarakat luas mengenai alat musik tradisional yang dikemas dan diinovasikan dengan nadanada yang baru agar terdengar menarik sekaligus melestarikan budaya Indonesia. Tidak kalah pentingnya tujuan terakhir pembentukan Kelompok Seni Musik Patrol Perkusi Bendho Agung yaitu membina anak-anak dan remaja yang bukan berlatar belakang dari anak seni untuk melestarikan budaya melalui seni musik, seni rupa (membuat ukiran-ukiran untuk kereta), dan seni tari untuk belajar bersama dalam bidang seni sehingga dapat melestarikan budaya Indonesia melalui alat musik dan tari tradisional.

Kegiatan yang dilakukan oleh Kelompok Seni Musik Patrol Perkusi Bendho Agung meliputi bermain alat musik tradisional patrol perkusi, menari tari tradisional, dan membuat dekorasi kereta. Dekorasi kereta sangat penting untuk memperindah sekaligus lambang Kelompok Seni Musik Patrol Perkusi Bendho Agung agar terkesan berbeda dan untuk meletakkan seluruh alat musik ketika acara. Alat musik yang digunakan Kelompok Seni Musik Patrol Perkusi Bendho sebagian besarnya merupakan alat musik daur ulang yang dikemas agar menjadi lebih indah dan menarik. Alat musik dari daur ulang barang-barang bekas yaitu gentong, dig dug atau kentongan dari kayu dan alat musik tradisional seperti kenong asli dari banyuwangi, dig dug, saron, rebana, kendang, drum plastik, drum besi, dan gong.

\subsection{Respon Adanya Kelompok Seni Musik Patrol Perkusi Bendho Agung}

Berdasarkan temuan penelitian adanya Kelompok Seni Musik Patrol Perkusi Bendho tidak akan berjalan dengan lancar tanpa adanya dukungan dari masyarakat Desa Gadungsari. Adapun beberapa pendapat dari masyakarat dan anggota Kelompok Seni Musik Patrol Perkusi Bendho dengan hadirnya Kelompok Seni Musik Patrol Perkusi Bendho sebagai berikut.

Kelompok Seni Musik Patrol Perkusi Bendho Agung merupakan kesenian yang masih berusia muda namun, respon masyarakat sekitar dengan hadirnya Kelompok Seni Musik Patrol 
Perkusi Bendho Agung di daerah ini disambut baik oleh masyarakat meskipun masih ada pro dan kontra namun, mayoritas masyarakat sangat mendukung dalam melestarikan budaya dalam wadah Kelompok Seni Musik Patrol Perkusi Bendho Agung. Kesenian yang baru didengar oleh warga Desa Gadungsari mendapatkan respon yang positif karena hadirnya kesenian ini melahirkan anak-anak serta remaja yang kreatif dalam memainkan alat musik dan tari tradisional serta menambah data hiburan yang baru. Kekhasan suara dan alat musik yang dimainkan sangat enak didengar ditambah terdapat tari-tarian yang mengiringi membuat masyarakat suka dan mendukung dengan adanya Kelompok Seni Musik Patrol Perkusi Bendho Agung.

Kelompok Seni Musik Patrol Perkusi Bendho Agung memberikan sarana untuk belajar alat musik maupun tari tradisional karena dengan wadah Kelompok Seni Musik Patrol Perkusi Bendho Agung seluruh anggota diajari mulai dari nol dalam mengembangkan bakatnya tentang alat musik tradisional dan tari tradisional. Anggota Kelompok Seni Musik Patrol Perkusi Bendho Agung sangat senang dan mendukung dengan adanya kelompok seni ini untuk penyaluran bakat serta belajar mencintai kebudayaan Indonesia melalui alat musik dan tari tradisional yang diwadahi oleh Kelompok Seni Musik Patrol Perkusi Bendho Agung.

Pemerintah Desa Gadungsari memberikan respon yang sangat baik dan mendukung dengan adanya Kelompok Seni Musik Patrol Perkusi Bendho Agung karena dengan adanya kelompok seni ini dapat menyalurkan bakat-bakat generasi muda serta memberikan daftar kesenian baru yang ada di Desa Gadungsari. Kebanggaan terhadap Kelompok Seni Musik Patrol Perkusi Bendho Agung. Pemerintah Desa Gadungsari juga sangat bangga akan prestasi yang diperoleh Kelompok Seni Musik Patrol Perkusi Bendho karena dari prestasi ini dapat mengharumkan nama Desa Gadungsari melalui prestasi yang didapatkan. Meskipun dalam hal ini pemerintah Desa Gadungsari belum dapat membantu sepenuhnya Kelompok Seni Musik Patrol Perkusi Bendho Agung secara finansial terkait sarana yang masih menjadi penghambat Kelompok Seni Musik Patrol Perkusi Bendho Agung yaitu kostum tari agar tidak terkendala lagi perihal sarana prasarana. Respon karang taruna Desa Gadungsari dengan adanya Kelompok Seni Musik Patrol Perkusi Bendho mendukung, namun pada praktiknya karang taruna belum andil dan ikut serta dalam menumbuhkan nasionalisme melalui Kelompok Seni Musik Patrol Perkusi Bendho Agung.

\subsection{Cara Menumbuhkan Nasionalisme Remaja Melalui Kelompok Seni Musik Patrol Perkusi Bendho Agung}

Kelompok Seni Musik Patrol Perkusi Bendho Agung merupakan kelompok seni yang terdiri dari masyarakat Desa Gadungsari Kecamatan Tirtoyudo Kabupaten Malang khusunya masyarakat Kampung Dongki (MASPUNGKI) dengan memberikan serta menambah daftar kesenian baru khusunya di daerah Kabupaten Malang melalui alat musik patrol perkusi dengan nama Kelompok Seni Musik Patrol Perkusi Bendho Agung. Kesenian adalah salah satu isi dari kebudayaan manusia secara umum, karena dengan berkesenian merupakan cerminan dari suatu bentuk peradaban yang tumbuh dan berkembang sesuai dengan keinginan dan cita-cita yang berpedoman kepada nilai-nilai yang berlaku dan dilakukan dalam bentuk aktifitas berkesenian, sehingga masyarakat mengetahui bentuk keseniannya (Netrirosa, 2005:6). Nasionalisme merupakan salah satu yang perlu ditanamkan dan dikembangkan di dalam lingkungan masyarakat khususnya kepada remaja. Hal ini senada dengan yang diungkapkan oleh Wuryandani (2010:161) menyatakan bahwa nilai nasionalisme sangat penting 
ditanamkan karena saat ini banyak pengaruh luar yang tidak semuanya bersifat positif yang dapat mengikis rasa cinta tanah air atau cinta budaya remaja sebagai generasi penerus bangsa.

Kelompok Seni Musik Patrol Perkusi Bendho Agung dibentuk oleh masyarakat Kampung Dongki secara murni tanpa campur tangan pemerintah desa maupun karang taruna Desa Gadungsari sebagai bentuk upaya mencintai budaya Indonesia melalui alat musik dan tari tradisional. Upaya menumbuhkan jiwa nasionalisme pada generasi muda bangsa ini tidak hanya tanggung jawab pemerintah sebagai penyelenggara negara namun juga peran aktif masyarakat (Emirta, 2013:56). Dibentuknya Kelompok Seni Musik Patrol Perkusi Bendho Agung bertujuan untuk memperkenalnkan serta melestarikan budaya bangsa Indonesia melalui alat musik patrol perkusi khususnya bagi remaja Kelompok Seni Musik Patrol Perkusi Bendho Agung sebagai generasi penerus bangsa. Salah satu yang harus di tumbuhkan sikap nasionalismenya adalah generasi muda, karena merekalah kelak yang akan membawa bangsa ke depan maka generasi muda akan mendapatkan sebuah gambaran dan akan mengetahui maksud dari terbentuknya nasionalisme Indonesia (Alfaqi, 2016:209).

Cara menumbuhkan nasionalisme di kalangan remaja Kelompok Seni Musik Patrol Perkusi Bendho Agung yaitu dengan melakukan berbagai kegiatan seperti merakit sesis kereta hias, membuat dekor kereta hias, bermain alat musik tradisional seperti: kenong, dig dug, saron, rebana, kendang, drum plastik, drum besi, dan gong serta menari tarian tradisional yang dikolaborasikan dengan alat musik tradisional serta dengan aransemen khas buatan dari remaja Kelompok Seni Musik Patrol Perkusi Bendho Agung. Hal-hal yang dapat dilakukan untuk menumbuhkan rasa nasionalisme generasi muda adalah melestarikan kebudayaan yang ada di dalam negeri sendiri agar tidak dilupakan oleh generasi penerus bangsa (Lestari, 2019:26). Mendekatkan remaja dengan alat musik dan tari tradisional agar mereka tertarik kemudian barulah dibimbing dan diarahkan sesuai dengan pola tradisi, melalui hal tersebut dapat membuat anak-anak suka dengan alat musik dan tari tradisional adalah salah satu cara menumbuhkan nasionalisme di kalangan remaja Kelompok Seni Musik Patrol Perkusi Bendho Agung. Nasionalisme adalah pandangan yang bertujuan untuk mengembangkan rasa nasional berdasarkan pemahaman dan rasa cinta tanah air terhadap budaya lokal yang diketahui dan difahami (Aswasulasikin, 2020:64-65).

Memberikan tuntutan untuk menghafal lagu-lagu daerah dan lagu nasional hal ini dikarenan ketika bermain alat musik tradisional diatas kereta hias wajib hafal lagu yang diiringi, hal tersebut merupakan cara menumbuhkan nasionalisme di kalangan remaja Kelompok Seni Musik Patrol Perkusi Bendho Agung. Hal ini sejalan dengan pendapat yang diungkapkan Mustari (2011:195) bahwa lagu nasional harus diajarkan dan dihafal oleh anakanak sejak dini dan oleh seluruh warga Negara, sebab lagu-lagu tersebut membawa mereka kembali ke masa perjuangan orang tua mereka, para pahlawan, para tokoh kemerdekaan, dalam memerdekakan negeri ini dan dalam berjuang membangun negeri ini. Kepahlawanan kenegaraan perlu harus diperdengarkan kepada khalayak bahwa semangat itu ada dan akan terus ada.

Saat ini tidak ada kegiatan yang dilakukan remaja Kelompok Seni Musik Patrol Perkusi Bendho Agung dikarenakan pandemi. Namun, ada beberapa kegiatan yeng pernah dilakukan dalam menumbuhkan nasionalisme di kalangan remaja Kelompok Seni Musik Patrol Perkusi Bendho Agung yaitu membantu korban bencana alam dengan terjun langsung ke lokasi dan menggalang dana untuk di donasikan kepada korban bencana alam. Contoh kecil dalam 
penananman nasionalisme yaitu dengan mengajarkan remajan untuk guyub rukun membantu sesama seperti menjenguk orang yang sakit. Nasionalisme merupakan semangat, kesadaran, dan kesetiaan bahwa suatu bangsa itu adalah keluarga dan atas dasar rasa sebagai suatu keluarga bangsa (Lestari, Sri 2018:206).

\subsection{Bentuk Perwujudan Nasionalisme di Kalangan Remaja Kelompok Seni Musik Patrol Perkusi Bendho Agung}

Bermain alat musik tradisional patrol perkusi serta menari tarian tradisional merupakan bentuk perwujudan dari nasionalisme di kalangan remaja Kelompok Seni Musik Patrol Perkusi Bendho Agung. Bentuk perwujudan nasionalisme yang mendasar dari segi seni rupa yaitu kaos anggota dengan desain yang diinginkan seluruh anggota ada nuansa atau corak batik, hal tersebut telah menandakan wujud cinta tanah air. Tidak hanya mendapatkan ilmu mengenai alat musik dan tari wujud nasionalisme melalui Kelompok Seni Musik Patrol Perkusi Bendho Agung ini yaitu dengan mendapatkan pengetahuan akan jenis-jenis batik dan asal alat musik tradisional dari berbagai event. Adapun karakter nasionalisme yang tertanam dalam diri anak antara lain apresiasi terhadap budaya bangsa sendiri, menjaga kekayaan budaya bangsa, cinta tanah air, disiplin, menghormati keragaman budaya, suku, agama, dan kerja sama (Apriani, 2017:105).

Perwujudan nasionalisme di kalangan remaja Kelompok Seni Musik Patrol Perkusi Bendho Agung selanjutnya yaitu lagu yang dinyanyikan Kelompok Seni Musik Patrol Perkusi Bendho Agung berupa lagu-lagu nasional atau lagu modern bernuansa kebangsaan seperti "Garuda di Dadaku" yang dikolaborasikan dengan musik patrol perkusi hingga mengangkat Kelompok Seni Musik Patrol Perkusi Bendho Agung lolos hingga tingkat provinsi. Bukan hanya lagu nasional perwujudan nasionalisme dibuktikan dengan dimainkan dan dikolaborasikan musik tradisional dengan lagu-lagu daerah. Hal tersebut sesuai dengan pendapat Buasan (2012:10-11) bahwa merasa bangga sebagai bangsa Indonesia dan bertanah air Indonesia dengan turut serta dalam melestarikan kesenian daerah maka akan tercipta sumber daya manusia yang tidak sekedar berkualitas, namun memiliki rasa bangga dan cinta terhadap bangsa dan tanah air Indonesia.

Perwujudan nasionalisme remaja berikutnya yaitu tidak ada rendah hati atau minder remaja Kelompok Seni Musik Patrol Perkusi Bendho Agung ketika ikut karnaval dikelilingi sound system dengan suara yang lebih keras bermusik dj, tetapi mereka semakin semangat dan bangga bermain alat musik tradisional. Cinta tanah air harus dibuktikan dengan kata atau tindakan yang sejalan, yang menunjukkan sikap serba positif dalam kehidupan berbangsa dan bernegara, mereka yang cinta tanah air akan bersungguh-sungguh menjalankan kewajiban dimanapun dan dalam posisi apapun berada (Nashir, 2013:97). Hal ini dapat kita lihat ketika remaja lebih mudah dipengaruhi oleh teman-temannya daripada ketika mereka masih kanakkanak, ini berarti bahwa pengaruh orangtua semakin lemah. Anak remaja berperilaku dan mempunyai kesenangan yang berbeda bahkan bertentangan dengan perilaku dan kesenangan keluarga, contoh yang umum adalah dalam hal kesenangan musik yang kesemuanya harus mutakhir. Hal ini banyak terjadi karena remaja sering juga menjadi terlalu percaya diri (over confidence) dan ini bersama-sama dengan emosinya yang biasanya meningkat, mengakibatkan sulit menerima nasihat dan pengarahan orangtua dan banyak dari mereka yang ikut-ikutan dan merasa tidak percaya diri akan keunikan dan kemampuan mereka . 
Tujuan perwujudan nasionalisme di kalangan remaja Kelompok Seni Musik Patrol Perkusi Bendho Agung yaitu untuk menarik antusias remaja agar menyukai serta melestarikan alat musik tradisional dan tari tradisional. Tujuan dari segi lingkungan tempat Kelompok Seni Musik Patrol Perkusi Bendho Agung yaitu menggali bakat dibidang seni musik dan tari. Dari situlah kemudian terbentuk tujuan yang lain seperti anak-anak kemudian tau akan jenis musik slendro, pelog, jenis batik, jenis ukir.dan tari tradisional. Hal yang tidak terduga yaitu kegiatan yang pernah dilakukan Kelompok Seni Musik Patrol Perkusi Bendho Agung sebagai wujud nasionalisme di kalangan remaja yakni banyak prestasi yang pernah diraih diantaranya pada tingkat kecamatan, kabupaten hingga tingkat provinsi. Hal ini sesuai dengan tujuan adanya penanaman atau menumbuhkan nasionalisme, dimana nasionalisme wajib dilakukan oleh semua masyarakat khususnya para remaja sebagai generasi penerus bangsa apalagi di era globalisasi ini. Nasionalisme di kalangan remaja dapat dilakukan melalui pendidikan formal seperti sekolah dan juga melalui pendidikan non formal seperti halnya paguyuban, komunitas, dan lain sebagainya. Pendidikan non formal tidak kalah pentingnya dengan pendidikan formal karena kita dapat memperoleh pengetahuan melalui pengalaman maupun organisasi seperti halnya paguyuban maupun kelompok-kelompok kesenian yang berada di lingkungan masyarakat.

\subsection{Kendala yang Dihadapi dalam Menerapan Nasionalisme di Kalangan Remaja Kelompok Seni Musik Patrol Perkusi Bendho Agung}

Penerapan nasionalisme di kalangan remaja Kelompok Seni Musik Patrol Perkusi Bendho Agung ini berjalan dengan lancar akan tetapi dalam menerapkan nasionalisme di kalangan remaja juga tidak lepas dari kendala-kendala yang dihadapi Kelompok Seni Musik Patrol Perkusi Bendho Agung dalam menerapkan nasionalisme adalah sebagai berikut.

\subsubsection{Kendala dari Segi Waktu}

Kendala dari segi waktu dalam menerapkan nasionalisme dikalangan remaja Kelompok Seni Musik Patrol Perkusi Bendho Agung yaitu waktu yang bentrok, waktu bentrok yang dimaksud adalah waktu sekolah dengan waktu event yang berbarengan sehingga dalam penerapannya terkadang menjadi terhambat hal ini dikarenakan mayoritas anggota merupakan anak atau remaja yang masih duduk di bangku sekolah. Hal-hal mendesak ini bertindak terhadap seseorang yang membuatnya tergoda untuk tidak bisa melepaskannya, sehingga cenderung menggunakan banyak waktu untuk memenuhinya (Gea, 2014:781).

Kegiatan latihan tidak dilaksankan seminggu sekali karena sampai saat ini masih belum ada jadwal tetap untuk kegiatan latihan karena anggota masih belum siap jika kegiatan latihan dijadwalkan. Kegiatan latihan pasti Kelompok Seni Musik Patrol Perkusi Bendho Agung dilaksanakan ketika H-3 akan dilaksanakan acara, ikut parade, dan lomba.

\subsubsection{Kendala dari Segi Sarana}

Sarana yang dimiliki Kelompok Seni Musik Patrol Perkusi Bendho Agung sudah tergolong lengkap seperti alat musik tradisional seperti kenong, dig dug, saron, rebana, kendang, drum plastik, drum besi, gong, dan kereta hias milik Kelompok Seni Musik Patrol Perkusi Bendho Agung. Namun, masih terdapat kendala dari segi sarana yaitu belum ada kostum tari yang dimiliki Kelompok Seni Musik Patrol Perkusi Bendho Agung dikarenakan setiap event kostum yang dipakai selalu berganti hal ini dikarenakan menyesuaikan dengan 
tema. Hal ini karena selain alat-alat musik yang dibutuhkan untuk menunjang latihan, penari pasti membutuhkan kostum untuk berpantas ketika diundang dalam acara-acara tertentu.

\subsection{Solusi dalam Menghadapi Kendala Penerapan Nasionalisme Dikalangan Remaja Kelompok Seni Musik Patrol Perkusi Bendho Agung}

Berdasarkan temuan penelitian terdapat kendala yang dihadapi oleh Kelompok Seni Musik Patrol Perkusi Bendho Agung. Kendala yang dihadapi akan berdampak negatif dan mengalami kesulitan dalam proses menumbuhkan nasionalisme dikalangan remaja Kelompok Seni Musik Patrol Perkusi Bendho Agung. Oleh karena itu, Kelompok Seni Musik Patrol Perkusi Bendho Agung melakukan upaya-upaya untuk menuntaskan kendala-kendala yang dihadapi sehingga proses menumbuhkan nasionalisme dikalangan remaja Kelompok Seni Musik Patrol Perkusi Bendho Agung berjalan lancar. Hal ini sesuai dengan pernyataan dari Heridiansyah (2014:36) untuk menyelesaikan suatu kendala diperlukan kesepakatan solusi untuk mengumpulkan masukan mengenai jalan keluar yang memungkinkan dari orang-orang yang terlibat di dalamnya dan sering melakukan penyelesaian yang tidak dapat diterapkan atau tidak praktis dan carilak penyelesaian yang terbaik. Adapun upaya-upaya yang dilakukan Kelompok Seni Musik Patrol Perkusi Bendho Agung sebagai berikut.

\subsubsection{Solusi dari Segi Waktu}

Upaya mengatasi kendala waktu yang bentrok atau waktu yang berbarengan antara sekolah dan waktu event yaitu pembuatan surat izin oleh sekertaris Kelompok Seni Musik Patrol Perkusi Bendho Agung. Namun, jika event langsung dari Dinas Pariwisata maka surat izin akan dibuatkan langsung oleh Dinas Pariwisata yang selanjutnya akan diberikan kepada pihak sekolah agar memberikan izin kepada siswa siswinya ikut dalam event yang diikuti Kelompok Seni Musik Patrol Perkusi Bendho Agung. Time management adalah tindakan dan proses perencanaan dan pelaksanaan kontrol sadar atas sejumlah waktu yang digunakan untuk aktivitas tertentu, khususnya untuk meningkatkan efektivitas, efisiensi, dan produktifitas supaya bisa melakukan penggunaan paling baik atas waktu yang dimiliki (Gea, 2014:778).

Belum terdapat jadwal yang tetap untuk kegiatan latihan maupun berkumpul anggota Kelompok Seni Musik Patrol Perkusi Bendho Agung namun, terdapat waktu untuk kegiatan latihan yaitu dimulai pukul 19.00 sampai waktu yang tidak ditentukan. Melihat kendala dari segi waktu penjadwalan latihan maka upaya yang dilakukan dalam mengatasi kendala waktu yakni latihan dapat berganti sesuai dengan kesepakatan bersama. Hal ini dikarenakan melihat situasi dan kondisi lingkungan tempat berlatih Kelompok Seni Musik Patrol Perkusi Bendho Agung dan kegiatan latihannya sendiri meliputi memainkan alat musik dan berlatih menari.

\subsubsection{Solusi dari Segi Sarana}

Kendala yang dihadapi Kelompok Seni Musik Patrol Perkusi Bendho Agung dari segi sarana yaitu masih belum terdapat konstum tari. Solusi dalam menghadapi kendala tersebut dengan menyewa kostum tari di sanggar seni Turen dan solusi yang kedua yaitu meminjam kostum ke teman Pak Andri. Manajemen sarana san prasarana merupakan proses kegiatan perencanaan, pengorganisasian, pengadaan, pemeliharaan, penghapusan dan pengendalian logistik atau perlengkapan Soebagio dalam (Gusnia, 2019:1). 


\section{Simpulan}

Berdasarkan hasil penelitian mengenai menumbuhkan nasionalisme di kalangan remaja Kelompok Seni Musik Patrol Perkusi Bendho Agung di Desa Gadungsari Kecamatan Tirtoyudo Kabupaten Malang dapat diambil kesimpulan sebagai berikut: (1) Menumbuhkan nasionalisme di kalangan remaja Kelompok Seni Musik Patrol Perkusi Bendho Agung dilakukan dengan cara mendekatkan serta membimbing remaja kepada alat musik dan tari tradisional. Cara kedua melalui lagu yang dinyanyikan sekaligus diiringi alat musik tradisional patrol perkusi yaitu lagu-lagu daerah dan lagu nasional dengan sentuhan aransemen khas Kelompok Seni Musik Patrol Perkusi Bendho Agung. Penanaman nasionalisme juga dilakukan dengan cara memberikan tuntutan kepada remaja Kelompok Seni Musik Patrol Perkusi Bendho Agung untuk menghafal lagu-lagu daerah karena ketika berada diatas kereta dan memainkan alat musik wajib ikut serta menyanyi. Atas dasar tuntutan tersebut remaja Kelompok Seni Musik Patrol Perkusi Bendho Agung akan dengan sendirinya hafal lagu-lagu daerah. (2) Bentuk perwujudan nasionalisme dikalangan remaja Kelompok Seni Musik Patrol Perkusi Bendho Agung adalah kaos anggota ada nuansa atau corak batik, lagu yang dinyanyikan yaitu lagu nasional dan lagu daerah yang dikolaborasikan dengan musik tradisional patrol perkusi, bentuk perwujudan selanjutnya yaitu tidak ada rasa minder atau rendah hati remaja Kelompok Seni Musik Patrol Perkusi Bendho Agung ketika bermain alat musik tradisional dan menari tarian tradisional. Tujuan perwujudan nasionalisme dikalangan remaja Kelompok Seni Musik Patrol Perkusi Bendho Agung yaitu untuk menarik antusias remaja untuk menyukai serta melestarikan alat musik tradisional dan tari tradisional. Tujuan dari segi lingkungan tempat Kelompok Seni Musik Patrol Perkusi Bendho Agung yaitu menggali bakat dibidang seni musik dan tari. (3) Kendala yang dihadapi dalam menerapan nasionalisme dikalangan remaja Kelompok Seni Musik Patrol Perkusi Bendho Agung yaitu kendala dari segi waktu dan segi sarana. Kendala dari segi waktu yaitu waktu yang bentrok antara waktu sekolah dengan waktu event yang berbarengan karena mayoritas anggota merupakan anak atau remaja yang masih duduk di bangku sekolah dan belum terdapat jadwal tetap kegiatan latihan. Kendala kedua yaitu kendala dari segi sarana yaitu kurangnya kostum tari yang dimiliki Kelompok Seni Musik Patrol Perkusi Bendho Agung. (4) Solusi dalam menghadapi kendala penerapan nasionalisme dikalangan Remaja Kelompok Seni Musik Patrol Perkusi Bendho Agung dalam mengatasi kendala waktu yaitu dengan membuat surat izin oleh sekertaris Kelompok Seni Musik Patrol Perkusi Bendho Agung namun, jika event langsung dari Dinas Pariwisata maka surat izin akan dibuatkan langsung oleh Dinas Pariwisata dan solusi dalam menghadapi kendala waktu penjadwalan kegiatan latihan yakni dengan cara kesepakatan bersama para anggota. Solusi dalam menghadapi kendala dari segi sarana yaitu menyewa serta meminjam kostum tari merupakan bentuk solusi dalam menghadapi kendala sarana dalam penerapan nasionalisme dikalangan remaja Kelompok Seni Musik Patrol Perkusi Bendho Agung. Dengan adanya Kelompok Seni Musik Patrol Perkusi Bendho Agung dapat menumbuhkan nasionalisme terutama di kalangan remaja serta dapat memberikan daftar kesenian baru yang ada di Desa Gadungsari. Tidak hanya itu, dengan adanya Kelompok Seni Musik Patrol Perkusi Bendho Agung dapat mengharumkan nama Desa Gadungsari, Kecamatan Tirtoyudo, Kabupaten Malang dengan segala prestasi yang pernah maupun akan diraih oleh Kelompok Seni Musik Patrol Perkusi Bendho Agung.

\section{Daftar Rujukan}

Affan, M.H. (2016). Membangun Kembali Sikap Nasionalisme Bangsa Indonesia dalam Menangkal Budaya Asing di Era Globalisasi. Jurnal Pesona Dasar, 3(4), 65-72. DOI: https://jurnal.unsyiah.ac.id/PEAR/article/view/7542. 
Alfaqi, M.Z. (2016). Melihat Sejarah Nasionalisme untuk Memupuk Sikap Kebangsaan Generasi Muda. Jurnal Civics, 13(2), 209-216. DOI: https://journal.uny.ac.id/index.php/civics/article/view/12745/0.

Apriani, A., Sari, I.P.,\& Suwandi, I.K. (2017). Pengaruh Living Values Education (LVEP) Terhadap Penanaman Karakter Nasionalisme Siswa SD dalam Pembelajaran Tematik. Jurnal Taman Cendikia, 1(2), 102-112. DOI: https://jurnal.ustjogja.ac.id/index.php/tamancendekia/article/view/1947.

Aswasulasikin, A., Pujiani, S.,\& Hadi, Y. (2020). Penanaman Nilai Nasionalis Melalui Pembelajaran Budaya Lokal Sasak di Sekolah Dasar. Jurnal DIDIKA:Wahana Ilmiah Pendidikan Dasar, VI (1), 63-76. DOI: https://ejournal.hamzanwadi.ac.id/index.php/didika/article/view/2027.

Buasan, B. (2012). Mari Tumbuhkan Jiwa dan Semangat Nasionalisme. Perilaku Nasionalistik Masa Kini dan Ketahanan Nasional. Yogyakarta: Mata Bangsa.

Emirta, Y. (2013). Menumbuhkan Jiwa Nasionalisme Pada Generasi Muda Bangsa dan Peran Pemerintah Dalam Menumbuhkan Jiwa Nasionalisme Generasi Muda Bangsa Melalui Pendidikan Pembangunan Karakter. Journal of nonformal Education, 1(1), 54-68. DOI: http://jurnal.unw.ac.id:1254/index.php/AIJ/article/view/139.

Gea, A. (2014). Time Management: Menggunakan Waktu Secara Efektif dan Efisien. Humaniora, 5(2), 777-785. DOI: https://media.neliti.com//media/publications/167302-ID-time-management-menggunakanwaktu-secara.pdf.

Heridiansyah, J. (2014). Manajemen konflik dalam suatu organisasi. Jurnal STIE Semarang, 6(1), 34-49.

Ilyas. (2016). Pengelolaan Kursus Musik (Studi Pada Lembaga Kursus Musik 99 Jl. Pattimura Raya Ungaran Kabupaten Semarang). Journal of Nonformal Education and Community Empowerment, 5(1), 9-15. DOI: https://journal.unnes.ac.id/sju/index.php/jnfc/article/view/2803.

Lestari, E.Y. (2019). Menumbuhkan Kesadaran Nasionalisme Generasi Muda di Era Globalisasi Melalui Penerapan Nilai-nilai Pancasila. Andil Indonesia Jurnal Universitas Ngudi Waluyo, 1(1), 20-27. DOI: jurnal.unw.ac.id:1254/index.php/AIJ/article/download/139/133.

Lestari, S.U. (2018). Penanaman Nilai-nilai Nasionalisme dalam Pembelajaran Sejarah Lokal Perjuangan Rakyat Sukorejo Kelas XI di SMA Negeri 1 Sukorejo. Indonesian Journal of History Education, 6(2), 205215. DOI: https://journal.unnes.ac.id/sju/index.php/ijhe/article/view/27652.

Mustari, M. (2011). Nilai Karakter Refleksi untuk Pendidikan Karakter. Jakarta: PT Raja Grafindo Persada.

Nashir, H. (2013). Pendidikan Karakter Refleksi Berbasis Agama dan Kebudayaan. Yogyakarta: Multi Presindo.

Netrirosa, A. (2005). Pemeliharaan Kehidupan Budaya Kesenian Tradisional dalam Pembangunan Nasional. Jurnal e-USU Repository Universitas Sumatera Utara, 2(3), 1-8. DOI: http://repository.usu.ac.id/handle/123456789/1675.

Sugiyono. (2012). Metode Penelitian Kuantitatif dan R\&D. Bandung: Alfabeta.

Sugiyono. (2014). Metode Penelitian Kualitatif dan R\&D. Bandung: Alfabeta.

Wuryandani, W. (2010). Integrasi Nilai-nilai Kearifan Lokal dalam Pembelajaran untuk Menanamkan Nasionalisme di Sekolah Dasar. Proceding Seminar Nasional Lembaga Penelitian UNY, 7(1): 1-10. 